\title{
Three Year Prospective Study of Visual Function and Retinopathy in Diabetics With Improved Glycaemic Control
}

\author{
DIABETIC RETINOPATHY STUDY GROUP* ST THOMAS' HOSPITAL \\ London
}

\begin{abstract}
Summary
The visual function and degree of retinopathy was assessed, over a three-year period, in a cohort study of twenty-eight diabetics, in whom glycaemic control was improved by intensive monitoring and supervision of conventional therapies.

With the exception of visual acuity and some tests of visual field sensitivity, there was no significant change in visual functions or retinopathy; with improved control of blood glucose, these two visual functions showed a small initial deterioration and subsequently returned towards starting values. Six subjects required laser photocoagulation for progressive peripheral neovascularisation (including two subjects with peripheral new vessels), the six having a significantly longer duration of diabetes, slightly worse measures of extra-foveal retinal functions and a significantly greater reduction in haemoglobin $A_{1}$ concentration during the first six months of the study.

In this study, the improvement of blood glucose control by intensive supervision of conventional therapy did not appear to be associated with the significant acute deterioration of visual function or retinopathy that has been reported with the strict diabetic control by multiple daily insulin injections or continuous subcutaneous insulin infusion.
\end{abstract}

Some studies have reported that poor control of diabetes is associated with an increase in the severity of diabetic retinopathy in $\operatorname{man}^{1.2 .3}$ and in animals; ${ }^{4}$ others have suggested that improved control slows the rate of deterioration of retinopathy. ${ }^{5.6}$ More recently, there have been a number of reports suggesting that the rapid improvement of control by means of continuous sub-cutaneous insulin infusion (CSII) is associated with a deterioration of diabetic retinopathy, characterised by the appearance of cotton wool spots and the development of neovascularisation $;^{7,8,9,10,11.12} \mathrm{a}$ recent study showing a less marked deterioration of retinopathy with CSII has several defects, rendering true interpretation difficult. ${ }^{13}$

The present study, by using specialist nurses and home blood-glucose monitoring ${ }^{14}$ to improve control in a cohort of poorly controlled diabetics with established background retinopathy, was designed to test whether

${ }^{*}$ Department of Ophthalmology: R. A. Harrad, Iris Fund Research Registrar; A. P. Plumb, Iris Fund Research Registrar; G. E. Rose, Iris Fund Research Registrar; J. S. Shilling, Consultant. Department of Medicine: S. Prickett, Research Sister; B. Plumb, Research Sister; F. Shenouda, Research Fellow; P. H. Sonksen, Professor. Department of Community Medicine: R. W. Morris, Lecturer in Statistics.

Correspondence to: Professor P. H. Sonksen, Department of Medicine, St Thomas' Hospital, London SE1 7EH. 
changes in blood glucose control affected visual function or retinopathy.

\section{Patients and Methods}

Nine males and nineteen females were recruited, their mean age at entry to the study being 43 years (range 19-65 years) and mean duration of diabetes 17 years (range $1-40$ years). The number of subjects decreased during the study, with losses due to death, cataract, laser photo-coagulation, pregnancy and default (Table I); decisions for laser therapy were made after each visit, on the basis of fluorescein angiographic changes. At enrolment, all subjects had a Snellen visual acuity of $6 / 9$ or better in at least one eye and at least early background retinopathy; no subject had been given photocoagulation and no eye required immediate laser therapy, although two eyes had early peripheral new vessels. Four subjects were controlled on oral medications and 24 on insulin; all had poor diabetic control with $\mathrm{HbA}_{1}$ concentrations of greater than 10 per cent (normal range 6-8.5 per cent; reference 15) and none had experience of any form of home blood-glucose monitoring, although most had previously been asked to perform urine testing at home.

The subjects performed blood glucose monitoring between two and four times daily using Dextrostix (Ames) and a Glucochek meter (Medistron Ltd, Crawley, Sussex) and were reviewed approximately monthly by a research nursing sister specially trained in diabetic care, who gave advice about changes in diet, insulin dosage and type and about the interpretation of their blood glucose readings. At each visit $\mathrm{HbA}_{1}$ concentrations were measured using a microcolumn method. ${ }^{15}$

Subjects were assessed by one of three ophthalmologists (RAH, APP or GER) at the beginning of the study and at approximately $3,6,12,18,24,30$ and 36 months. In all cases the right eye only was studied, unless previous laser treatment or other disease (for example, cataract or amblyopia) made this impossible. The best corrected visual acuity was measured using a Snellen chart and a slit-lamp microscopic examination was peformed. The visual fields were assessed on a Goldmann perimeter using a size I spot and the filters $4 \mathrm{e}, 3 \mathrm{e}$, and $2 \mathrm{e}$; reading correction was supplied for the dimmest target if the subject was unable to read N5 test-type at $30 \mathrm{~cm}$ unaided. Subsequently the subject was dark-adapted for three minutes and the visual fields recorded on the Friedmann Mark II analyser, starting with a spot intensity appropriate for the subject's age at entry to the study. ${ }^{16}$ The colour vision was assessed using a Farnsworth-Munsell Hundred-hue test, although one colour-blind subject was excluded. The subject's pupils were then dilated and fundus photography and fluorescein angiography was performed using a Zeiss fundus camera.

Hammersmith grading of the colour photographs ${ }^{17}$ and micro-aneurysm counts from the fluorescein angiograms were peformed on a $30^{\circ}$ diameter fundus view centred on the fovea, using a masked-film assessment by one of three observers; there was good concordance between observers

Table I Number of subjects within each test group and number of subjects lost to study

\begin{tabular}{|c|c|c|c|c|c|c|c|c|}
\hline & \multicolumn{8}{|c|}{ Time of assessment (months) } \\
\hline & 0 & 3 & 6 & 12 & 18 & 24 & 30 & 36 \\
\hline \multicolumn{9}{|l|}{ Measurement } \\
\hline Visual acuity & 28 & 28 & 28 & 27 & 23 & 18 & 16 & 16 \\
\hline Goldman fields & 28 & 27 & 28 & 27 & 25 & 20 & 16 & 16 \\
\hline Friedman fields & 25 & 28 & 28 & 27 & 24 & 18 & 16 & 16 \\
\hline Hundred hue test & 11 & 24 & 27 & 26 & 25 & 20 & 16 & 16 \\
\hline Micro-aneurysms & 26 & - & 23 & 22 & 20 & 17 & 13 & 15 \\
\hline Hammersmith grading & - & & & & & & & \\
\hline Haemorrhages & 26 & - & 23 & 22 & 20 & 17 & 13 & 15 \\
\hline Exudates & 26 & - & 23 & 22 & 20 & 17 & 13 & 15 \\
\hline Total patients & 28 & 28 & 28 & 27 & 25 & 22 & 18 & 16 \\
\hline Missed visits & 0 & 0 & 0 & 0 & 0 & 2 & 2 & 0 \\
\hline Laser therapy after visit & 0 & 0 & 1 & 2 & 1 & 1 & 1 & 0 \\
\hline Other losses after visit & 0 & 0 & 0 & 0 & $2^{*}$ & $2 \#$ & 0 & 0 \\
\hline Defaulters after visit & 0 & 0 & 0 & 0 & 0 & 1 & 1 & 0 \\
\hline
\end{tabular}

*2 deaths (myocardial infarction).

\#1 cataract, 1 pregnancy. 
(Appendix). In addition, the presence and area of cotton-wool spots was assessed.

\section{Statistical Methods}

In practice, some monthly $\mathrm{HbA}_{1}$ measurements were missing for each subject (due, for example, to defaulted visits or damaged specimens). To facilitate the relating of observed measures of retinopathy to $\mathrm{HbA}_{1}$ concentrations, it was necessary to calculate predicted $\mathrm{HbA}_{1}$ concentrations for each subject at the eight study times $(0,3,6,12,18,24$, 30 and 36 months); this was achieved by the fitting of a two-part exponential regression equation, this also tended to compensate for random variability of the measurements. In each individual subject, the predicted $\mathrm{HbA}_{1}$ concentrations were related to visual and retinal variables by the use of withinsubject regression analysis. ${ }^{18}$ For each variable, the coefficients derived from each of the 28 subjects were combined to provide an indication of the effect of changes of $\mathrm{HbA}_{1}$ concentration on visual function and retinal status.

Goldmann field tests were scored by assessing the area enclosed by each isopter $\left(\mathrm{cm}^{2}\right)$. Friedmann field tests were scored by summating the point values and expressing the value as a percentage of the age-related maximum score. Visual acuity was represented on a scale from 1 to $9(<6 / 60,6 / 60$, $6 / 36,6 / 24,6 / 18,6 / 12,6 / 9,6 / 6$ and 6/5).

\section{Results}

There was a significant reduction in the mean predicted $\mathrm{HbA}_{1}$ concentrations, from $11.7 \pm 0.45$ per cent (standard error of mean) at entry, to $9.8 \pm 0.3$ per cent at three months and $9.3 \pm 0.3$ per cent at six months. Twentythree of the 28 subjects achieved a $\mathrm{HbA}_{1}$ concentration within the normal range on at least one occasion during the first twelve months of the study. The improved $\mathrm{HbA}_{1}$ concentration was maintained from the first to the third study year (Fig. 1). The six subjects requiring laser photocoagulation later in the study (including the two with new vessels at entry to the study) had a significantly greater reduction in $\mathrm{HbA}_{1}$ concentration during the first

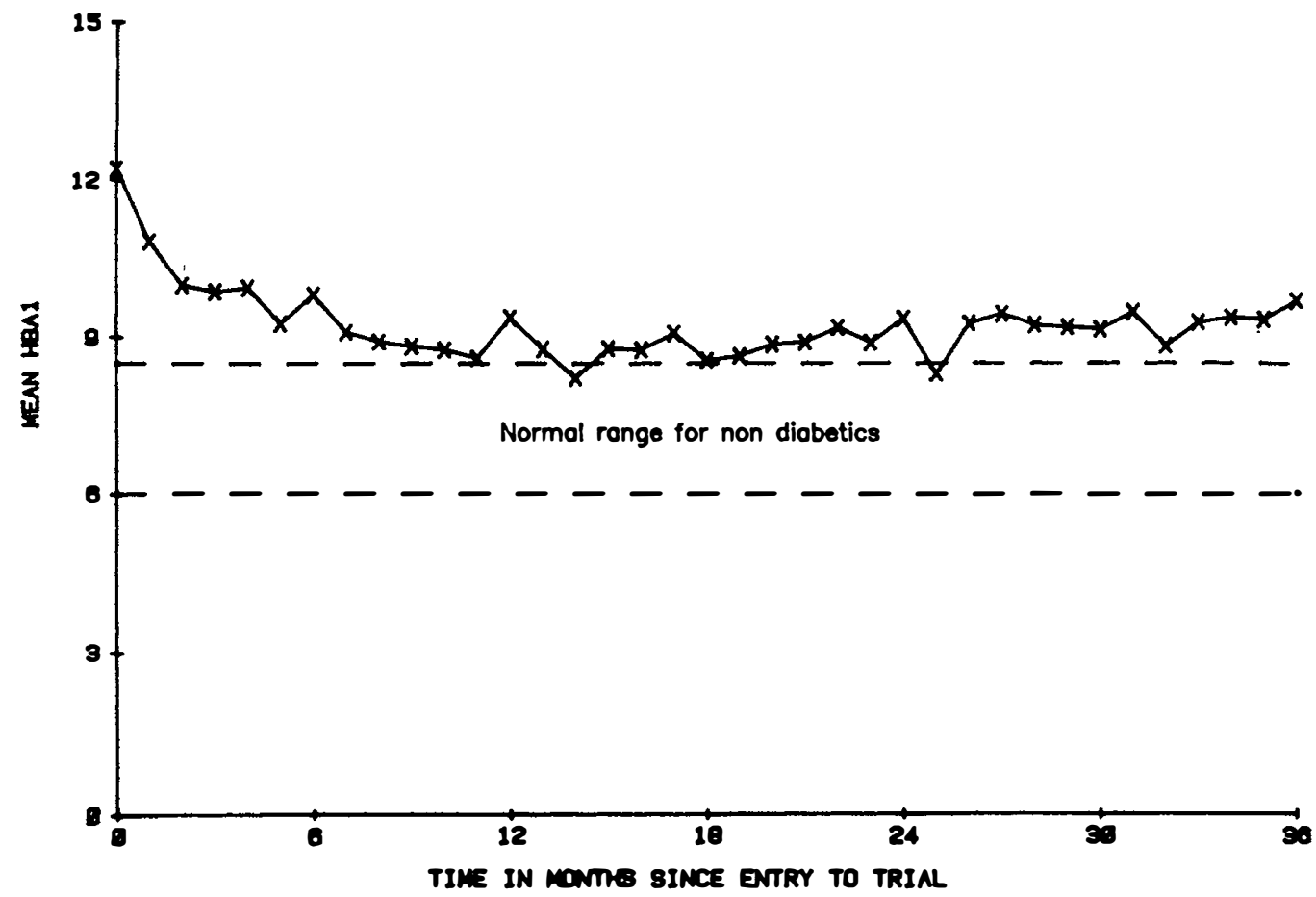

Fig. 1. Variation of mean Haemoglobin $A_{1}$ concentrations with time after entry into study. Each point represents the mean of the percentage $H b A_{1}$ concentrations (as assayed) of up to 28 subjects. The normal range of $H b A_{1}$ concentration for the assay method used is $6.0-8.5$ per cent, indicated by the broken lines on the figure. 
three (2.8 per cent reduction) and first six months (3.6 per cent) than that of the nonlaser group (1.6 per cent at three months, $\mathrm{P}<0.05$ and 2.1 per cent at six months, $\mathrm{P}<0.05)$; the laser group did, however, have a higher, although statistically insignificant, $\mathrm{HbA}_{1}$ concentration on starting the study (mean 12.4 per cent, compared with 11.5 per cent in the non-laser group; $\mathrm{P}<0.2$ ). Although subjects requiring laser photocoagulation were of similar age to those not requiring therapy (mean age at entry 40 and 44 years, respectively; NS), the laser group had a significantly greater duration of diabetes (laser group mean 28 years, range 7 to 40 years; non-laser group mean 15 years, range 1 to 29 years: $\mathrm{P}<0.05$ ).

There was a significant association between I4e Goldmann scores and $\mathrm{HbA}_{1}$ concentration $(\mathrm{P}<0.05)$ and between visual acuity and $\mathrm{HbA}_{1}(\mathrm{P}<0.05)$; both of these visual functions deteriorated slightly during improved glycaemic control but subsequently improved. A one per cent decrease (improvement) in $\mathrm{HbA}_{1}$ concentration was associated with a reduction of visual field by $2.6 \mathrm{~cm}^{2}$ and the percentage of subjects with a Snellen acuity of $6 / 9$ or better declined from 100 per cent at enrolment to 89 per cent at 6 months and 85 per cent at 12 months.

Other measures of visual function did not show significant associations with $\mathrm{HbA}_{1}$ concentration over the three years of the study. In addition, it emerged in retrospect that, at the visit before laser therapy, those subjects subsequently given laser therapy had Goldmann field scores lower than average in $14 / 18$ of the tests in the six subjects ( 18 tests $=3$ isopters $\times 6$ subjects $)$; similarly, Friedmann field scores were less than mean values in all 6 laser subjects.

Fundus details, as assessed from colour photographs and fluorescein angiograms, showed only minor changes: Five subjects developed cotton-wool spots during the first six months of the study; in two subjects the $\mathrm{HbA}_{1}$ concentration had fallen to within the normal range by 6 months and in the other three it was still greater than 8.5 per cent. Comparing the 7 subjects who attained $\mathrm{HbA}_{1}$ concentrations inside the normal range by six months with the other 21 subjects, there was no significant difference in the incidence of cotton-wool spots or of subsequent laser therapy (Fisher's Exact testing). Mean macular micro-aneurysm counts varied during the three year study (Fig. 2), but those in the laser group did not appear to be significantly different from the others; in contrast, all laser subjects that were photographed had retinal haemorrhages and exudates, generally of more severe grading.

\section{Discussion}

All subjects had improved glycaemic control (as reflected in the improved $\mathrm{HbA}_{1}$ concentrations) with the institution of home blood-glucose monitoring and stricter, personalised supervision by a nursing sister; this improvement agrees with the experience of other studies. ${ }^{14}$

The improvement in the control of blood glucose was not associated with any major, acute deterioration of visual functions, although a transient and small decline in Goldmann visual field sensitivity and Snellen visual acuity was of statistical significance. The eye disease in six of 26 subjects in the present study (23 per cent; excluding two defaulters) progressed to require laser panretinal photocoagulation for progressive neovascularisation; the ultimate glycaemia control in this group was not significantly different from the others, although the laser group had a significantly greater duration of diabetes, probably a worse control prior to the study (higher initial $\mathrm{HbA}_{1}$ values) and a significantly greater decrease in $\mathbf{H b A}_{1}$ concentration during the first six months of the study. A slightly lower peripheral retinal sensitivity in the pre-laser group is indicated by the rather lower Goldmann and Friedmann visual field scores; measures of foveal function, namely colour discrimination and visual acuities, were similar in both groups. Both subjects starting the study with peripheral new vessels progressed to require laser therapy.

In contrast to the findings of the present study, there have been several reports of a deterioration of visual function and retinopathy with the more rapid glycaemic control provided by $\operatorname{CSII}^{7,8,9},{ }^{10,11,12,13}$ or multiple daily insulin injections. ${ }^{11}$ Moreover, the significant 


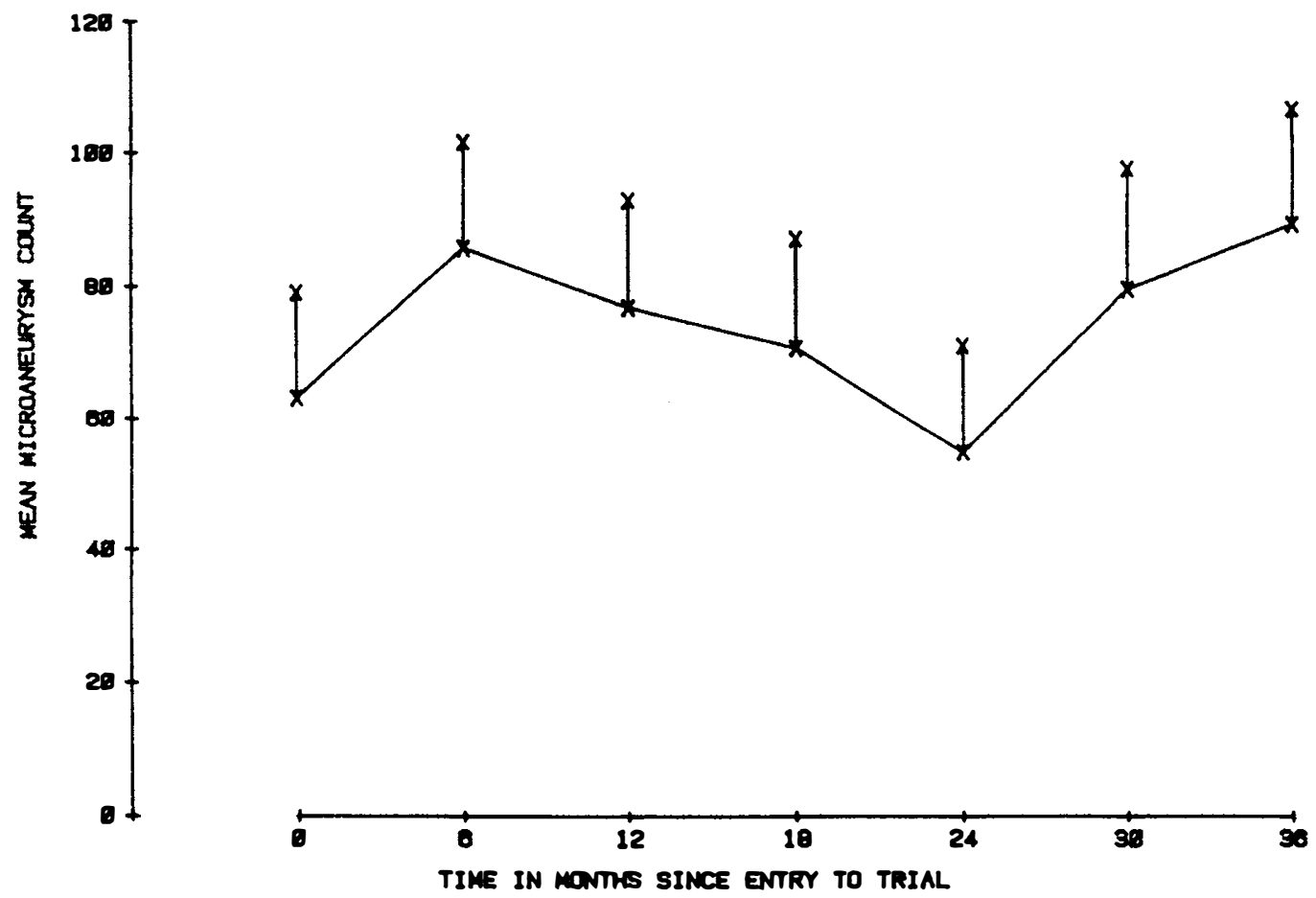

Fig. 2. Variation of mean microaneurysm counts with time after entry to the study. Each point represents the mean (with standard error of mean, $S E$ ) number of microaneurysms present in the fluorescein angiograms of the central fundus $\left(30^{\circ}\right.$ diameter area), in up to 26 subjects. The number of subjects examined at each point during the study is summarised in Table $I$.

increase in cotton-wool spots in subjects controlled rapidly with multiple injections (5-7 daily) or with CSII, as reported by the Aker group,${ }^{11}$ did not occur in the present study.

In a case-control study of insulin-dependent diabetics in whom control was improved by techniques almost identical to those of the present study, ${ }^{19}$ retinopathy (assessed from counts of microaneurysms and cotton wool spots and areas of retinal haemorrhages and exudates) progressed to the same degree in the study and the control groups, despite a significantly improved $\mathrm{HbA}_{1}$ concentration in the study group. In addition, 6 out of 36 of the study group progressed to neovascularisation, in contrast to only 2 out of the 38 in the control group.

An increase in micro-aneurysm count during the first six months of the present study was followed by a progressive fall over the next eighteen months, and then a subsequent rise (Fig. 2). This profile possibly reflects either a six month lag in an effect of improved glycaemia (improvement causing a reduction in retinal micro-vascular abnormalities), an observation that would accord with the rate of structural 'turnover' of retinal microaneurysms-estimated as between 6 and 18 months 'half-life', ${ }^{20}$ or, alternatively, a worsening of retinal biochemical microenvironment as a result of decreased blood glucose.

We gratefully acknowledge the expert photographic assistance of Mr Richard Dewhirst and also the extensive funding of this project by the Iris Fund for the Prevention of Blindness (APP, RAH and GER) and the British Diabetic Association.

\section{Appendix}

Micro-aneurysm counts were assessed from masked fluorescein angiograms by one of three observers (APP, RAH or GER). To test the degree of concordance between obser- 
vers, five angiograms were read independently by all three. There were no significant differences between the observers; the between-observer standard deviation was 3.45 compared with a between-subject standard deviation of 13.1.

\section{References}

${ }^{1}$ Pirart J: Diabetes mellitus and its degenerative complications. A prospective study of 4400 patients observed between 1947 and 1973. Diabe tes Metab 1977, 3: 97-107, 173-82, 245-56.

${ }^{2}$ Dornan TL, Mann JI, Turner R: Factors protective against retinopathy in insulin dependent diabetics free of retinopathy for 30 years. $\mathrm{Br}$ Med J 1982, 285: 1073-7.

${ }^{3}$ Doft BH, Kingsley LA, Orchard TJ, Kuller L, Drash A, Becker D: The association between long-term diabetic control and early retinopathy. Ophthalmology 1984, 91: 763-8.

${ }^{4}$ Engerman RL, Bloodworth JMB, Nelson S: Relationship of microvascular disease in diabetes to metabolic control. Diabetes 1977, 26: 760-79.

${ }_{5}^{5}$ Job D, Eschwege E, Guyot-Argenton C, et al.: Effect of multiple daily insulin injections on the course of diabetic retinopathy. Diabetes 1976, 25: 463-9.

${ }^{6}$ Miki E, Fukuda M, Kuzuya T, Kosaka K, Nakao K: Relation of the course of retinopathy to control of diabetes, age and therapeutic agents in diabetic Japanese patients. Diabetes 1969, 18: 77380.

${ }^{7}$ Lawson PM, Champion MC, Canny C, et al.: Continuous subcutaneous insulin infusion does not prevent progression of proliferative and pre-proliferative retinopathy. $\mathrm{Br} J$ Ophthalmol 1982, 66: 762-6.

${ }^{8}$ Hooymans JMM, Ballagooi EV, Schweitzer NM, Doorenbos H, Reitsma WD, Sluiter WJ: Worsening of diabetic retinopathy with strict control of blood sugar. Lancet 1982, ii: 438.

${ }^{9}$ Lauritzen T, Frost-Larsen K, Larsen H-W, Deckert $T$, Steno Study Group. Effect of one year of near normal blood glucose levels on retinopathy in insulin dependent diabetics. Lancet 1983, i: 200-4.

${ }^{10}$ Lauritzen T, Frost-Larsen K, Larson H-W Deckert T, Steno Study Group. The effect of near-normal blood glucose levels upon retinopathy: Two year follow-up. Diabetologia 1983, 25: 174-5.

${ }^{11}$ Dahl-Jorgensen K, Brinchmann-Hansen O, Hanssen KF, Sandvik L, Aagenaes O, Aker Diabetes Group. Rapid tightening of blood glucose control leads to transient deterioration of retinopathy in insulin dependent diabetes mellitus: the Oslo study. Brit Med J 1985, 290: 811-15.

12 Kroc Collaborative Study Group. Blood glucose control and the evolution of diabetic retinopathy and albuminuria. A preliminary multicenter trial. New Engl J Med 1984, 311: 365-72.

${ }^{13}$ Friberg TR, Rosenstock J, Sandborn G, Vaghefi A, Raskin P: The effect of long-term near normal glycaemic control on mild diabetic retinopathy. Oph thalmology 1985, 92: 1051-7.

${ }^{14}$ Sonksen PH, Judd SL, Lowy C: Home-monitoring of blood glucose. Lancet 1978, i: 729-32.

${ }^{15}$ Baron MD, Sonksen PH, Shenouda FS: Microcolumn method for $\mathrm{HbA}_{1}$ determination. Lancet 1980, i: $1114-6$.

${ }^{16}$ Friedmann AI: Serial analysis of changes in visual field defects employing a new instrument to determine the activity of diseases involving the visual pathways. Ophthalmologia 1966, 152: 1-12.

${ }^{17}$ Oakley N, Hill DW, Joplin GF, et al.: Diabetic retinopathy. 1. The assessment of severity and progress by comparison with a set of standard fundus photographs. Diabetologia 1967, 3: 402-5.

${ }^{18}$ Baker RJ and Nelder JA: The GLIM system. Release 3. Generalised Linear Interactive Modelling. Oxford: Numerical Algorithms Group, 1978.

${ }^{19}$ Holman RR, Dornan TL, Mayon-White V et al.: Prevention of deterioration of renal and sensorynerve function by more intensive management of insulin-dependent diabetic patients. A two-year randomized prospective study. Lancet 1983, 1: 204-8.

${ }^{20}$ Kohner EM and Dollery CT: The rate of formation and disappearance of microaneurysms in diabetic retinopathy. Europ J Clin Invest 1970, 1: 167-71. 